\title{
Resistance of glass window subjected to high velocity soft impact
}

\author{
Lucia Figuli $^{1,}$, Romana Erdelyiová ${ }^{1}$, Daniel Papán ${ }^{2}$ and Zuzana Papánová ${ }^{2}$ \\ ${ }^{1}$ University of Žilina, Faculty of Security Engineering, Univerzitná 8215/1, 01026 Žilina, Slovak \\ Republic \\ ${ }^{2}$ University of Žilina, Faculty of Civil Engineering, Univerzitná 8215/1, 01026 Žilina, Slovak \\ Republic
}

\begin{abstract}
Nowadays glass as a structural material is spread use not only for buildings in form of façade, windows and columns, but as well as for the protection of displays of electronical devices, or windows used in aeroplanes. In all cases is essential to describe the behaviour of glass panels under the high velocity soft impact caused for example by bird strike, icicles impact and bumps. In this paper the aim is to describe method to estimate the resistance of glass against drop soft impact and the comparison with the real tests.
\end{abstract}

\section{Introduction}

Even though glass windows are not considered as a bearing structural elements, study the dynamic response of glass elements are essential and required for various motivations. Not only for the nature of glass as a brittle material with small elastic deformation and without significant plastic deformation, absorbing rather little energy prior to fracture, even those of high strength, the glass as a material is interesting. To find the resistance to impact of brittle materials has been the subject of many recent studies because of its various applications responding very sensitively to impact loading. The main attention is paid to discover the real behaviour under the impact load of glass structural elements in form of glass façade [1] and columns [2]. Studying the response of glass windows on different extreme loads is essential for the protection of people. It is important to determine so called burglary resistance, i.e. ability of the glass windows to resist of burglary attack with various classes of tools, manual and electrical ones. Defining the vulnerability of persons so called soft targets, the second group of extreme dynamic load has to be considered [3, 4]. Behaviour of blast loaded windows is reported in [5] and beams in [6]. Deformation and damage mechanisms of laminated glass windows subjected to high velocity soft impact caused by bird strike were analysed in [7]. A glass plate subjected to impact at different loading rates using two methods: a compression split Hopkinson pressure bar and the normalized drop ball test were analysed in [8]. A failure criterion for laminated glass in case of impact is presented by Pyttel in [9]. Symmetric plate-impact tests of borosilicate glass projectiles into borosilicate glass targets were performed in [10].

* Corresponding author: lucia.figuli@fbi.uniza.sk 


\section{High velocity soft impact}

Impact loading accompanying by elevated velocity is caused for example by bird strike on the aeroplane windows (two elements moving with two different velocities), on building fenestrations (element with high velocity impacting element with zero velocity), icicles impact on glass roof (element with high velocity impacting element with zero velocity), bumps in burglary attacks (repetitive impact of element with high velocity, generally not rigidly constant to the element with zero velocity) or the same bump by person hitting the glass with the shoulder.

To describe the real structural behaviour on the high velocity soft impact is essential to know the dynamic characteristic and behaviour of impactor and studied structure. High velocity soft impact is standardly idealised by the impact of steel ball in form of free ball drop or in form of pendulum (see Fig. 1).

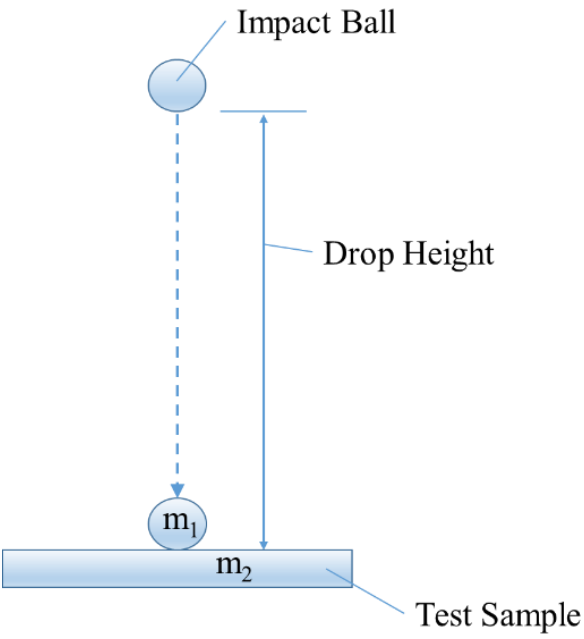

a)

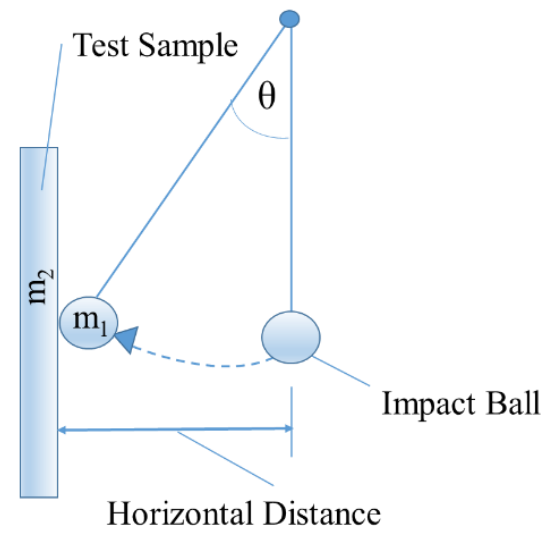

b)

Fig. 1. Normative impact ball test a) Drop ball test, b) Pendulum test.

On the previously described tests two standards for glass are based [11]:

- EN 356 Glass in building - Security glazing - Testing and classification of resistance against manual attack. The standard divides windows into two classes depending on type of test. In the first 5 levels, the test is based on the drop of the ball. The test is carried out using a steel ball with the mass of $4.11 \mathrm{~kg}$ for classes P1A to P5A and an axe for classes $\mathrm{P} 6 \mathrm{~B}$ to $\mathrm{P} 8 \mathrm{~B}$. The ball is dropped on the test sample several times from different defined heights according to the resistance class.

- EN 12600 Glass in Building - Pendulum test - Impact test method and classification for flat glass. The glass is subjected to a test where rubber tires of $50 \mathrm{~kg}$ are released into the glass pane at different heights. A three-digit rating are given to the glass, e.g. 3B2 or $3 \mathrm{C} 1$ depending on the limited height of the pendulum the type of rupture of damaged glass. The standard classifies tests into three major resistance classes.

\subsection{Analysis method}

Considering approximated approach, presented research problem is a mechanical SDOF system characterised by the condition before the impact and after the impact. Where $m_{1}$ is 
mass of the steel ball, $m_{2}$ is a mass of glass (Fig. 1). Initial velocity of ball is $v_{1}$, initial velocity of window $v_{2}$ is equal 0 . Momentum of the system is constant, momentum before the impact is equal to the momentum after the impact.

Hence we can write

$$
m_{1} \cdot v_{1}=m_{2} \cdot v_{2}+\int_{t_{1}}^{t_{2}} F(t) d t
$$

Because of the very short duration of the impact, force impulse can be neglected and so

$$
m_{1} \cdot v_{1}+m_{2} \cdot v_{2}=m_{1} \cdot u_{1}+m_{2} \cdot u_{2}
$$

where $u_{1}$ and $u_{2}$ are velocities after the impact. The ratio of the final to initial relative velocity between two objects after they collide is defined as a coefficient of restitution (3)

$$
\varepsilon=\frac{\left(u_{1}-u_{2}\right)}{\left(v_{1}-v_{2}\right)}
$$

Montaine and al. in [12] published the results of experimental investigation made on the setting of coefficient of restitution between glass plate and steel ball depending on the impact velocity (see Fig. 2).

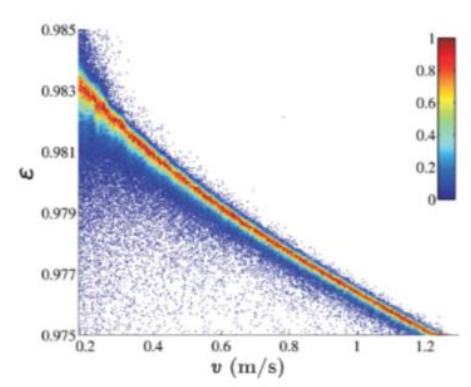

Fig. 2. Coefficient of restitution steel ball - glass plate depending on the impact velocity [12].

Final velocity of the window, after the impact is

$$
u_{2}=\frac{v_{1}}{1+\frac{m_{2}}{m_{1}}}(1+\varepsilon)
$$

Equation of motion after the impact for the mass 2 (window) can be defined as

$$
y=y_{0} \sin \left(\omega_{0} t+\varphi_{0}\right)
$$

Initial conditions are as follows $t=0, y=0, \dot{y}=u_{2}$, integral constants are $\varphi_{0}=0$

$$
\begin{gathered}
y_{0} \omega_{0}=u_{2} \\
y_{0}=\frac{u_{2}}{\omega_{0}}=u_{2} \sqrt{\frac{m_{2}}{k}}
\end{gathered}
$$

With the spring stiffness $k$. After the derivation of equation of motion, velocity is obtained

$$
\dot{y}=\omega_{0} \cdot y_{0} \cos \left(\omega_{0} t+\varphi_{0}\right)=\omega_{0} \cdot y_{0} \sin \left(\omega_{0} t+\frac{\pi}{2}+\varphi_{0}\right)
$$

Deriving of equation of motion, acceleration is achieved

$$
\ddot{y}=-\omega_{0}{ }^{2} \cdot y_{0} \sin \left(\omega_{0} t+\varphi_{0}\right)=\omega_{0}{ }^{2} \cdot y_{0} \sin \left(\omega_{0} t+\pi+\varphi_{0}\right)
$$


The spring stiffness $k$ depend on the stiffness between the glass plate and frame and the condition of structural bearing stiffness.

\subsection{Experimental laboratory testing}

Full scale experiments focused on the soft high velocity impact were performed. Two different type of window samples with total size of $1.21 \times 1.38 \mathrm{~m}$ were examined. The window frame was made of timber and PVC for possible comparison of the anchorage system. The nominal thickness of monolithic glass plate was $3 \mathrm{~mm}$ for the wooden specimen, and $4 \mathrm{~mm}$ for the PVC frame. Regarding the size of glass, the dimensions where defined from the total size of window samples and the frames in use. Accordingly, glass surface was $1.20 \times 1.05 \mathrm{~m}$ for the wooden frame and $0.81 \times 0.97 \mathrm{~m}$ for the PVC window. Dynamic impact experiments, based on the pendulum test, were performed on the windows (see Fig. 3). Steel ball impacted the window in the centre of glass plate. The overall sample was attached to a rigid metal frame.

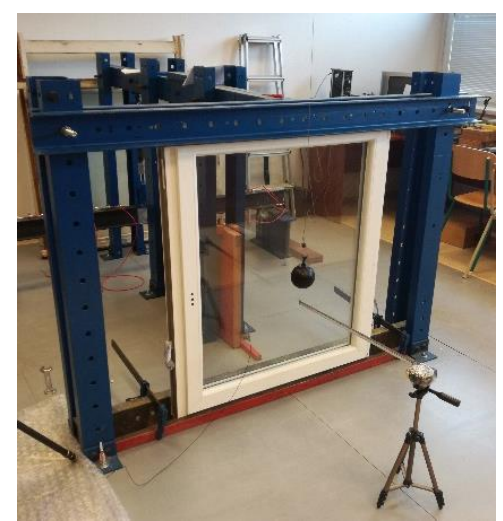

a)

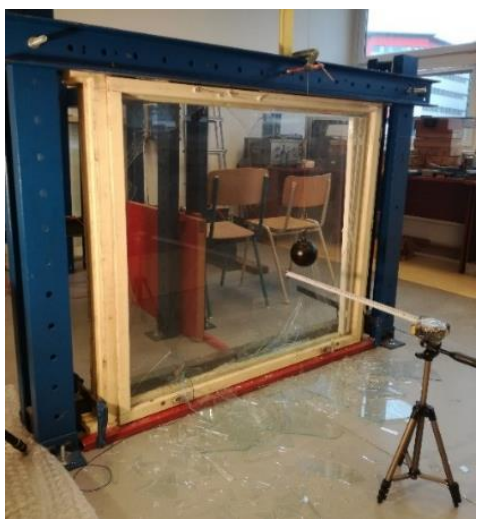

b)

Fig. 3. Experimental impact testing a) PVC frame b) Timber frame.

As an impactor, two steel balls with nominal weight of $2.644 \mathrm{~kg}$ and $4.571 \mathrm{~kg}$ were used, drop height (i.e., horizontal distance between the ball and the window) were incrementally increased to the limit distance where the damage of glass plate occurred. For each drop test, accelerations were measured using a set of sensors positioned in the lower part of glass (right side, at a distance of $0.2 \mathrm{~m}$ from the edge). A high-speed camera (FASTEC TS3100SC4256 Imaging) was also used, to investigate the impact velocity based also on slow motion registrations.

\section{Results and conclusions}

Totally 8 tests were conducted to obtain the damage of the window panels with the pendulum tests. Impact high was incrementally increasing to the limit damage value, entirely 90 soft impacts were completed. To describe the behaviour of the glass panel under the soft impact loading, essential characteristics were set. Overall impact energies were 
calculated according to (10). Where the maximum impact velocity was set using slow motion records from the high-speed camera

$$
E=\frac{1}{2} m v^{2}
$$

The maximum impact velocity of each test is presented in Table 1, as a function of ball size and level of impact energy, when damage of glass panel occurred.

Table 1. Impact resistance of windows under different ball sizes and impact energy.

\begin{tabular}{|c|c|c|c|}
\hline $\begin{array}{c}\text { Sample } \\
\mathbf{N}^{\circ}\end{array}$ & $\begin{array}{c}\text { Type of } \\
\text { window frame }\end{array}$ & $\begin{array}{c}\text { Impact horizontal } \\
\text { distance [m] }\end{array}$ & $\begin{array}{c}\text { Impact } \\
\text { energy [J] }\end{array}$ \\
\hline 1 & wood & 1.30 & 7.72 \\
\hline 2 & wood & 0.90 & 3.36 \\
\hline 3 & wood & 1.40 & 8.90 \\
\hline 4 & PVC & 0.15 & 19.75 \\
\hline
\end{tabular}

According the previously mentioned research the expected decay of coefficient of restitution with increasing impact velocity was observed (approximately with the exponential decay), the approximated values based on the decay of restitution are reported in the Table 2. As well as the final velocity of the windows were calculated based on ball mass, window mass, registered ball impact velocity from experimental testing and the coefficient of restitution. Calculated final velocity of the window is compared with the registered final velocity obtained from experimental testing. From the comparison sufficient correspondence is noticed. To calculate the velocity of the window after the impact is quit complex because of the ambiguous portion of window structure cooperating in the test. As a window mass, whole windows approximated weight were considered in the calculation, but the windows were fixed in the steel frame and it is not sufficiently clear the portion of collaborating structure (if only glass panel, or only PVC or timber frame or steel fixing frame or their mutual cooperation).

Table 2. Comparison of calculated and experimentally measured final velocity of the window.

\begin{tabular}{|c|c|c|c|c|c|c|}
\hline Sample No & $\begin{array}{c}\text { Ball mass } \\
{[\mathbf{k g}]}\end{array}$ & $\begin{array}{c}\text { Window } \\
\text { mass [kg] }\end{array}$ & $\begin{array}{c}\text { Ball } \\
\text { impact } \\
\text { velocity } \\
{[\mathbf{m} / \mathbf{s}]}\end{array}$ & $\begin{array}{c}\text { Coefficient } \\
\text { of } \\
\text { restitution } \\
\mathbf{\varepsilon}[-]\end{array}$ & $\begin{array}{c}\text { Final velocity } \\
\text { of the } \\
\text { window } \\
\text { calculated } \\
{[\mathbf{m} / \mathbf{s}]}\end{array}$ & $\begin{array}{c}\text { Final velocity } \\
\text { of the window } \\
\text { experiment } \\
{[\mathbf{m} / \mathbf{s}]}\end{array}$ \\
\hline 1 & 2.64 & 25.18 & 2.42 & 0.97 & 0.46 & 0.30 \\
\hline 2 & 2.64 & 25.18 & 1.60 & 0.97 & 0.30 & 0.20 \\
\hline 3 & 2.64 & 25.18 & 2.59 & 0.96 & 0.48 & 0.32 \\
\hline 4 & 4.57 & 58.44 & 2.94 & 0.96 & 0.42 & 0.37 \\
\hline
\end{tabular}

Consequent dynamic analyses of the window loaded by impact have to be done. To obtain dynamic characteristics as deflection, acceleration, stiffness constant $k$ have to be known. To gaining the real value of stiffness constant extending experimental testing is 
currently conducting. Afterwards impact resistance can be set and compared with the experimental obtained impact resistance.

The work was supported by the Internal Grant Scheme of Faculty of Security Engineering, University of Zilina from the grant No. 2019/10.

\section{References}

1. C. Bedon, X. Zhang, F. Santos, D. Honfi, M. Kozłowski, M. Arrigoni, L. Figuli, D. Lange. Constr. Build. Mater. 163 (2018)

2. C. Bedon, R. Kalamar, M. Eliasova. Compos. Struct. 182 (2017)

3. L. Figuli, S. Lichorobiec. Communications: scientific letters of the University of Žilina, 20, 2 (EDIS 2018)

4. L. Figuli, V. Kavický, Š. Jangl, Z. Zvaková. Communications: scientific letters of the University of Žilina, 20, 2 (EDIS 2018)

5. L. Figuli, Z. Zvaková, C. Bedon, Procedia Eng. 192 (2017)

6. L. Figuli, C. Bedon, Z. Zvaková, Š. Jangl, V. Kavický. Procedia Eng. 199 (2017)

7. I. Mohagheghiana, Y.Wanga, J. Zhoua, L. Yua, X. Guob, Y. Yanb, M. N. Charalambidesa, J. P. Deara. Int. J. Solids Struct. 109 (2017)

8. S. Bouzida, A. Nyoungue, Z. Azari, N. Bouaouadja, G. Pluvinage. Int. J. Impact Eng. 25 (2001)

9. T. Pyttel, H. Liebertz, J.Cai. Int. J. Impact Eng. 38 (2011)

10. S. Chocron, D. D. Barnette, T. J. Holmquist, C. E. Anderson Jr., R. P. Bigger, T. Z. Moore. Journal of Dynamic Behavior of Materials. 2 (2016)

11. R. Jankura, L. Figuli. Transactions of the VSB - Technical University of Ostrava, Safety Engineering Series. 14, 2 (2019)

12. M. Montaine, M. Heckel, C. Kruelle, T. Schwager, T. Poschel. Phys. Rev. E. 84 (2011) 